\title{
Species and Other Evolving Lineages as Feedback Systems
}

\author{
Matthew J. Barker*
}

\begin{abstract}
This paper proposes a new and testable view about the nature of species and other evolving lineages, according to which they are feedback systems. On this view, it is a mistake to think gene flow, niche sharing, and trait frequency similarities between populations are among variables that interact to cause some further downstream variable that distinguishes evolving lineages from each other, some sort of "species cohesion" for example. Instead, gene flow, niche sharing, similarities between populations, and other causal variables feed into each other-instances of these at earlier times help cause instances of these same variables at later times. And any lineage-identifying cohesion just is the recurrence or cycling of these feedback relations within metapopulations over generations. Such cohesion can then be represented as variable $M$ within multi-dimensional variable spaces, where values of $M$ vary dynamically with the frequency and magnitude of feedback relations. Related conditions for being a species or other evolving lineage are then clarified. To argue for the development and testing of this view, the paper shows how it improves upon others.
\end{abstract}

\section{Keywords}

evolving lineage $\bullet$ species problem $\bullet$ species cohesion $\bullet$ feedback system $\bullet$ evolutionary unit $\bullet$ species concept

Part of the special issue Species in the Age of Discordance, guest-edited by Matthew H. Haber and Daniel J. Molter.

*Concordia University, 1455 de Maisonneuve Blvd. W., Montreal, Quebec, Canada, H3G 1M8, matthew.barker@concordia.ca

Received 30 November 2017; Revised 15 October 2018; Accepted 1 November 2018 doi:10.3998/ptpbio.16039257.0011.013 


\section{Introduction}

Memorably in Nature, Jerry Coyne likened recalcitrant debates between species experts to barnacles on a whale, saying they "retard slightly the progress of the field" $(1992,290)$. However, experts have been happy to agree on at least this: species are evolving lineages. ${ }^{1}$ The importance of that putative fact, and of agreement about it, have been emphasized for over twenty years (Ereshefsky 1992a; Mayden 1997; de Queiroz 1998). Recent review works reaffirm both (e.g., Camargo and Sites 2013; Zachos 2016). But this lends some urgency to the unhappy fact that the exact nature of the implicated evolving lineages remains unclear (Haber 2013, 341; Richards 2010, 142; Barker and Wilson 2010; Pigliucci 2003, 598). Great, species are evolving lineages-but what are those, exactly?

To help with that evolving lineage problem, a main aim of this paper is to address it with a new theory. This proposes that in some and perhaps many cases being an evolving lineage is being a metapopulation feedback system. Technicalities aside, such a lineage is an active, dynamic, fluid thing, analogous to a functioning termite mound. The mound is a system sustained (with fluctuations) by feedback relations between $\mathrm{O}_{2}: \mathrm{CO}_{2}$ ratios, duct geometry, ambient conditions, and termite building behaviors (Turner 2008). Analogously an evolving lineage system features recurring feedback, though between quite different variables, including between earlier and later instances of gene flow, niche sharing, and trait frequency similarities between populations. The recurring feedback often diachronically sustains the lineage system through perturbations, ensuring it is no mere metapopulation and rather is something more self-sustaining that snakes its way through evolutionary space at temporal and spatial scales we struggle to conceptualize.

More technically, such a system has a property called metapopulation feedback cohesion, represented by variable $M$. Values of this variable vary dynamically with the frequency and magnitude of feedback relations between causal variables within the metapopulation feedback system. Below, exact conditions for being an evolving lineage are proposed in terms of $M$ and multi-dimensional variable spaces that help represent the contrasting values $M$ can take in various groups of populations. The variable spaces can also help better specify familiar ideas about species and other evolving lineages, and to empirically test some of those ideas.

The paper's conclusion is not that the feedback theory of evolving lineages is true or probably true, or even that we now have enough reason to adopt it. It would be preposterous for a first paper on a theory of this sort-and by a philosopher-to aim so high. This paper must instead be devoted to clarifying core concepts, empirical assumptions, and predictions, and to lending these the initial plausibility that would motivate the later modeling and testing that any claims to truth or adoption would require. Accordingly, the paper's conclusion is that it would be worthwhile for some of the interdisciplinary community of researchers working on species and evolving lineages to collaboratively further develop and empirically test the feedback theory of evolving lineages elaborated here.

The paper's overall argument for that conclusion involves showing how the feedback theory can improve upon existing theories of evolving lineages that underlie various species concepts. For example, while many species concepts imply that evolving lineages of the species type are distinguished partly by so-called "species cohesion" (see Brooks and McLennan 2002; Barker and Wilson 2010; de Queiroz 1998, 68), some underlying theories of evolving lineages imply that this cohesion is an effect diachronically downstream of, caused by, and thus in a sense separate from causal variables such as gene flow, niche sharing, and so on (see Barker and Wilson 2010). In contrast, the feedback theory proposes the relevant cohesion just is (or is realized or implemented simultaneously by) the feedback relations involving causal variables. There is no

\footnotetext{
${ }^{1}$ Or segments of such lineages. See de Queiroz (1998).
} 
need to posit some further diachronically downstream thing beyond the causal variables and feedback relations themselves.

Some other extant theories do not imply the relevant cohesion is some separate downstream thing; instead they describe it as some overall state of causal integration between populations. However these alternative theories (e.g., Hull 1976; Grant 1980; Wiley 1981; de Queiroz 1998; Ereshefsky 2001) have so far been vague, offering none of the precision about causal variables and interactions that would help frame subsequent quantitative modeling and testing. The feedback theory begins getting more exact, stating and vividly depicting conditions for being an evolving lineage which advise new focus on recurring or cycling feedback, the potential importance of which has been overlooked when thinking about the nature of evolving lineages.

The feedback theory also clarifies how trait frequency similarities may play surprising causal roles within feedback relations - how they may be causal variables just like gene flow and niche sharing and so on. This motivates us to think more carefully about a widely perceived opposition between, on one hand, theories that base the nature of evolving lineages in causal relations, and, on the other, theories that base it in similarity (e.g., Hull 1976; Ereshefsky 2001). For instance Hull once lamented that some authors think trait similarities are more "fundamental" than interbreeding to evolving lineages of the species type, while he oppositely urged that interbreeding is more "fundamental" (1981, 145). Those sorts of fundamentality claims become dubious upon recognizing both interbreeding and trait similarities as just two among other important causal variables, between which it is the recurring feedback relations that constitute lineages. However, this new view of lineage constitution also leaves open, and may help clarify the reasons for thinking, that non-causal forms of similarity are not among the conditions constituting evolving lineages, even if they are among important diagnostic conditions or grounds for inductions and explanations appealing to lineages.

Readers already familiar with how existing theories could be improved upon may wish to skip now to Sections 6-9, which unpack the details of the feedback theory of evolving lineages. The sections prior to those clarify what the evolving lineage problem is about (Section 2), how it is subtly distinct from related problems (Section 3), how existing attempts to solve it can be sorted and criticized (Section 4), and how this yields lessons for new theories to heed (Section 5). It is then that Sections $6-9$ unpack the feedback theory and show it heeds the identified lessons, with Section 10 summarizing the overall argument.

\section{What the Evolving Lineage Problem is About}

Although the evolving lineage problem involves the very nature of evolving lineages being less clear than we would like, we can start with a minimal characterization and clarify basic terms.

Here 'evolving lineage' minimally means a group of populations that actively evolve together by partaking in evolutionary processes that connect them (Ereshefsky 1992a). They are frequently called "evolutionary units" (Ereshefsky 1991) and described as dynamic or "active" (Ereshefsky 1992a, xiii; and see Eldredge and Cracraft 1980; Wiley 1981) and "functional" (Baum 2009, 74). To borrow David Hull's words, they "evolve, split, bud off new species ... etc." (Hull 1981, 146).

Several authors have noted a distinction between this type of lineage and the monophyletic clades that are also often called lineages and recognized as taxa when reconstructing phylogenies

\footnotetext{
${ }^{2}$ As we will see, some of the candidate connecting processes are driven partly by population level properties, and yet some of the candidate metapopulations will not be monophyletic clades well suited to phylogenetic analysis. So there will be a sense in which we sometimes are discussing matters that fall in between the levels that Willi Hennig labeled "phylogenetic" and "tokogenetic", respectively $(1966,29)$.
} 
(e.g., Cracraft 1989a; Kimbel and Rak 1993; de Queiroz 1998; Baum 2009). Due to this distinction, such clades are not the focus of this paper. ${ }^{3}$

As groups of populations, the evolving lineages of interest here are metapopulations. This distinguishes them from the many other types of lineage we find at different levels or scales of biological hierarchies and which may be said to evolve, such as mtDNA lineages, gene lineages, and so on (Haber 2012). ${ }^{-}$I use 'metapopulation' to mean any group of populations, each made up of organisms. 5 On this use of the term, only some metapopulations will count as evolving lineages.

When referring to such lineages, many authors have implicitly or explicitly had only species in mind. But others have implied that some more and some less inclusive metapopulations may also be evolving lineages (Ereshefsky 1991; Barker and Wilson 2010). An ecumenical way to frame this is to say that when authors use the term 'species' to refer to a category of evolving lineages, it is possible - and up for further investigation - that this is a sub-category belonging to a broader category of evolving lineages. Granted, it may turn out that the sub-category associated with species is of so much more interest than the others that we should eventually reserve our use of the term 'evolving lineage' for just that sub-category. But my feedback theory will for now use 'evolving lineage' in the more inclusive way, while having to draw mostly upon discussions of species for its input material. Moreover, it may turn out that we should recognize an even more inclusive use of 'evolving lineage', so that the kind of evolving lineages that the feedback theory is about are just one among several kinds, perhaps with some species being of the feedback sort and other species of other sorts. ${ }^{6}$ The feedback theory proposes to be about only some rather than all evolving lineages, though its potential to simultaneously respect and integrate pluralist ideas should become clear.

\section{The Problem Itself}

The problem, as intimated most recently by John Wilkins (2018, ch. 14), is that we lack a relatively exact, comprehensive, and widely accepted theory of what evolving lineages are, even though so many authors have claimed these are fundamental units in biology.

\footnotetext{
${ }^{3}$ It is clear that the evolving lineages discussed here are probably often not monophyletic clades, with some authors arguing that they cannot be (e.g., de Queiroz 1998). This doesn't imply that my project is of no interest to phylogeneticists. Baum (2009) clarifies that well-known phylogeneticists such as Hennig and Wiley and de Queiroz nonetheless view species as evolving lineages in the present sense.

${ }^{4}$ As metapopulations, evolving lineages are surely composed in various ways by lower level lineages (Haber 2012). This will matter to a full understanding of the lineages I focus on, though will be set aside for this paper's upstream aim of outlining a new direction in which we might begin building a fuller understanding.

${ }^{5}$ There are disputes about what, exactly, the terms 'metapopulation', 'population', and 'organism' should mean. For present purposes I must take these terms as well enough understood, and I provisionally presuppose something like Millstein's interactionist view of metapopulations and populations (2010) and Wilson's tripartite view of organisms (2005). Caveats: Millstein's stipulation that all members of a metapopulation or population are conspecific needn't and shouldn't be adopted a priori in the present discussion of evolving lineages, and I am open to both pluralist and conventionalist takes on 'metapopulation', 'population', and 'organism' (e.g., Barker and Velasco 2013; Stegenga 2014).

'In other words, an "evolving lineage pluralism" akin to "species pluralism" is an option I leave open.

${ }^{7}$ Several other authors (e.g., Haber 2013, 341; Richards 2010, 142; Pigliucci 2003, 598) have implied the same when discussing views that offer a theory of evolving lineages, and some of those views will be discussed below. Notice that although it is tempting to infer from the lack of an exact, comprehensive, and widely accepted theory of evolving lineages that it is hopeless to search for such a theory, the history of science shows such an inference is itself suspicious. History suggests verdicts often should wait for exact and comprehensive theories to evaluate (Stanford 2010), and that, however frustrating for our own careers, this can take centuries longer than we have so far been working on the concept of an evolving lineage.
} 
To avoid dead ends and talking past one another, it is crucial to clarify this problem by distinguishing it from closely related ones, such how to detect (or diagnose) evolving lineages. Recent advances in so-called species delimitation methods (see Camargo and Sites 2013), the merger of phylogenetic systematics and phylogeography (Edwards 2009), and the integration of traditional and more genomic methods of lineage detection (Dayrat 2005; Will et al. 2005; Bond and Stockman 2008; Padial et al. 2010; Schlick-Steiner et al. 2010; Schmid-Egger et al. 2017) give grounds for thinking we have made significant progress on the problem of detecting evolving lineages. But as several detectors themselves emphasize, that problem is primarily epistemological or operational while the evolving lineage problem is primarily ontological or theoretical (e.g., Camargo and Sites 2013). Knowing how to detect or tell that a thing is an evolving lineage is not necessarily the same as knowing what conditions are responsible for making a thing an evolving lineage. The former type of knowledge often rests largely on measuring properties that correlate (in telling ways for us) with being an evolving lineage, while the latter is about learning the conditions that underlie those correlations and constitute being an evolving lineage. Progress of the first sort often outstrips progress of the second for long periods of time. Researchers made great advances in using imaging technology, including X-ray radiographs as early as 1896, to tell when someone had cancer, even though many fine details about underlying conditions constituting cancer were yet to come (Grigg 1965).

So to address the evolving lineage problem is to develop a theory about which conditions constitute being an evolving lineage. 8 This is not (yet anyway) a search for the surely vast number of long and winding etiological pathways leading to conditions that make something an evolving lineage. Rather, for now, it is about clarifying constitutive conditions themselves-those that suffice in usual contexts to make a metapopulation an evolving lineage, regardless of the paths by which those conditions were achieved. Return to cancer: there are conditions that constitute a cell or cells being cancerous, and there are also (a great many) etiological pathways that can lead to those conditions.

A search for constitutive conditions should also be distinguished from related but more metaphysical debates about whether these linages are sets, individuals, natural kinds, and so on (e.g., Ghiselin 1974; Hull 1976; Kitcher 1984; Boyd 1999). Those debates are downstream of the constitution problem because we cannot settle whether evolving lineages are individuals, sets, kinds, or what have you, without learning more specifically which conditions constitute

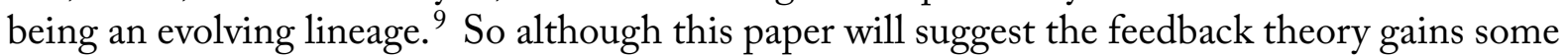
of its plausibility from getting more exact about views of evolving lineages that have motivated claims about their metaphysical status, such status is not a primary focus here.

Perhaps it is the detection problem that seems most relevant to the evolving lineage problem and its focus on constitutive conditions. And recent progress in the detection of evolving lineages has informed my feedback theory to some degree. But unfortunately there has been very little explicit attempt to use the detection work to inform our views of evolving lineage constitution. Instead, much detection work has proceeded as though the constituting conditions are settled enough and we can focus just on the detection (Camargo and Sites 2013; Zachos 2016,

\footnotetext{
${ }^{8}$ This needn't implicate any dubious essentialism. The heterogeneity within metapopulations suggests a good theory of evolving lineage constitution will abandon traditional essentialism in favour of more liberal views, on which various sets of conditions can each, in usual contexts, make a metapopulation an evolving lineage (Wilson, Barker, and Brigandt 2007).

${ }^{9}$ Echoing Hull (1976) and others, Crane (2004, especially 165-6) argues for this point, with respect to species in particular.
} 
108-9).10 Thus, rather than dwelling primarily on recent detection work, I will primarily turn to the sources that detectors themselves have turned to: species concepts.

\section{Existing Views of Evolving Lineages}

Species concepts are distinguished from each other in part by the definitions of 'species' they each propose plus elaborations of those definitions. Many specialists now distinguish between species concepts that are strictly epistemological (or operational), and those that are ontological (or theoretical) (Mayden 1997; Zachos 2016).11 The latter class is the relevant one here, and it can itself be sub-divided in several ways.

The sub-division used below starts from the fact that ontological species concepts tend to be based on a shared and very general idea, one that is seldom noted but which different researchers specify in different ways, leading to different ontological species concepts. The general idea is that one or another pattern of cause-and-effect associates with being a species. In addition to there being different ways of specifying this pattern, there is implied disagreement about which parts of the pattern are constitutive of being a species-are the parts of the pattern that a theoretical definition of 'species' should refer to as definitive.

That general idea is in fact old. Darwin expressed a version of it when saying "intercrossing plays a very important part in nature in keeping individuals of the same species, or of the same variety, true and uniform in character" (Darwin 1859, 103). According to that version the pattern of cause-and-effect that associates with being a species involves intercrossing as a cause and character uniformity as effect. ${ }^{12}$ Below, more contemporary ontological species concepts are sub-divided into those that specify the general idea in a cause-focused way, and those that do not. We'll see how these two classes are underpinned or motivated by two different views of evolving lineages. ${ }^{13}$ As figure 11 summarizes, I will argue that, so far, none of these views of lineages are both exact and comprehensive about lineage constitution. But they contain strengths to build upon.

\subsection{Examples of cause-focused ontological species concepts and some problems}

Proponents of cause-focused species concepts define 'species' by appeal to the causes that they think are most important within whichever cause-and-effect pattern they associate with species.

\footnotetext{
${ }^{10} \mathrm{It}$ is very tricky business to determine what should count as settled enough. Settled enough for what? There are many reasons aside from detection that biologists and philosophers of biology may want a better theory of evolving lineage constitution. But even if detection is your only interest, it is risky to suppose that a better constitution theory will be of little detection help. This is partly because the history of science shows that impressive detection progress often gets even better with progress on constitution problems (often called conceptual problems) - think again of cancer. But it is also because the supposition of "little help" is about a better theory that we have not yet developed. Without some researchers developing the theory, how can we tell it will be of little detection help? In any case, subsequent sections in the text clarify existing views of evolving lineage constitution in a way that suggests further developments in this area would be worth attempting for many purposes.

${ }^{11}$ Which species concepts should be classified as epistemological and which ontological is a delicate matter. I roughly follow Barker's (2017) sorting of concepts.

${ }^{12}$ Other things Darwin said about species have generated debate about whether he believed the species category to be objective. One way to express his ambiguity on the matter is to say he thought the cause-and-effect pattern in question was reasonably objective (with some vagueness and variation objectively present no doubt), but also thought it was sometimes arbitrarily that experts identified just species with this pattern, since the pattern seems to sometimes hold for things other than groups deemed species, and other times does not hold for some of the groups recognized as species. The quoted passage shows he thought it sometimes held for varieties too, for example.

${ }^{13}$ This is sometimes explicit in the authors' discussions of their definitions of 'species', other times implicit. Barker clarifies this in terms of underpinning (2010, 86ff.), Ereshefsky in terms of motivation (1992b, 682).
} 


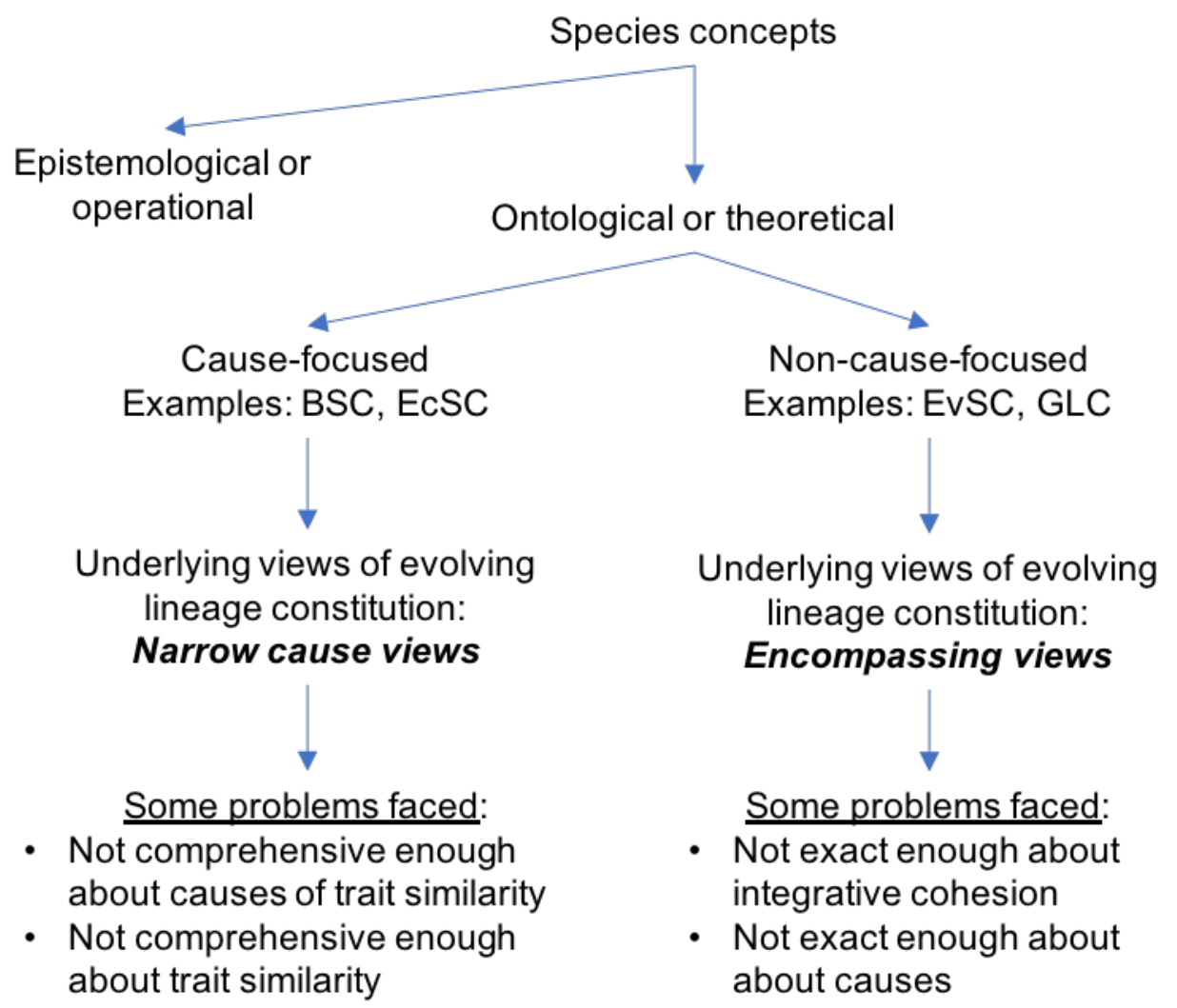

Figure 1: Some Species Concepts and Problems for Them Sorted

Subsequent elaborations of, and rationale for, these definitions often discuss distinguishing effects as well, but the effects are not a definitional focus.

For example, in his 2000 version of the biological species concept (BSC) Mayr wrote "I define biological species as groups of interbreeding natural populations that are reproductively isolated from other such groups" (2000b, 17). This appeals to a two-fold cause-genes flowing between conspecific populations (interbreeding), and genes not flowing between those and other populations (reproductive isolation)—without suggesting what the effect in question is. In Mayr's associated discussions he sometimes roughly followed Darwin by implying "phenotypic uniformity" is a distinguishing effect (e.g., 1963, 521-22, 2000a, 161). 14 And it seemed to be phenotypic discontinuities he had in mind when he said it was the job of a species concept to answer the questions "Why is not the organic world a single continuity? Why has nature ...favored the discontinuities among the species?" (Mayr 2000a, 161; see also Coyne and Orr 2004). But he also explicitly qualified that the effect of phenotypic uniformity within a species, and its flip side of phenotypic discontinuity between species, was not to be a focus of the definition of 'species' itself (e.g., 2000b, 17). So, while Mayr thought these uniformity effects are parts of the cause-and-effect pattern associated with being a species, he seemed to exclude them from the parts of the pattern also deemed constitutive of being a species.

By "phenotypic uniformity" Mayr had mostly in mind the phenotypic traits of organisms, but the uniformity he referenced was at the population level. It referred to frequencies of these traits being more similar between conspecific populations than between these and out-group

\footnotetext{
${ }^{14}$ As we'll see Mayr had in mind a type of population level phenotypic uniformity, and Darwin likely was thinking more at the organism level, or at least without the benefit of precision about the population level afforded by population genetics. Also, Mayr sometimes identified "genetic cohesion" as a distinguishing effect and suggested this was not simply a form of similarity though perhaps involved similarity (Mayr 1963, 521-22).
}

○ OPEN ACCESS - PTPBIO.ORG 
populations (Mayr 1963, 2000a, 161; also see Templeton 1989, 159; Coyne and Orr 2004, 26; Baum et al. 2013, 327).

It is common for proponents of cause-focused species concepts to have some such form of population level similarity in mind as distinguishing effect (Barker and Wilson 2010; more generally, see Beatty 1997). However, various forms of population similarities are implicated, including molecular or genetic similarities (e.g., Mallet 1995), and sometimes similarity or uniformity goes by other names, including 'homogeneity' and especially 'cohesion' (e.g., Ellstrand 2014; Grant 1980; see Barker and Wilson 2010; Ereshefsky 2001, 1991; Mishler and Brandon 1987). Moreover, various degrees of similarity or cohesion are discussed, including populations becoming homogenized in terms of just a few highly adaptive genes that are spread widely between and across them (e.g., Morjan and Rieseberg 2004). While proponents of cause-focused species concepts often specify the different kinds and degrees of similarities with the precision of quantitative population genetics, they nonetheless share Mayr's preference for keeping these effects outside the focus of their respective definitions of 'species'. Their focus is on causes.

But there is disagreement about which causes are "main" or "most important", and that's what differentiates cause-focused species concepts from each other. We have seen how the BSC privileges gene flow as a cause (also see Morjan and Rieseberg 2004). Van Valen's ecological species concept (EcSC) emphasizes shared niches or selection regimes (1976). Templeton's cohesion species concept (CSC) in a sense combines the BSC and EcSC by appealing to both sorts of cause (1989).

Underlying these different species concepts are differing views about which causes are most important for populations cohering as evolving lineages more generally, whether as species or more or less inclusive groups of populations. And each different underlying view of lineages tends to implicate just one or some very small set of causes as most important, whether it be gene flow, niche sharing, a combination of those, etc. So, let us say that these are each different narrow cause views of evolving lineages, underlying the different cause-focused species concepts. 15

A first problem for narrow cause views of evolving lineages stems from well-known criticisms of the species concepts they underlie. Each is too narrow on its own. In many cases, for instance, there are many important causes of the population level similarities in question (de Queiroz 1998, 2007), and often it is their interactions that matter most. Analyses suggest that excluding several of these causes from those parts of the cause-and-effect pattern(s) deemed constitutive of being a species or other evolving lineage, in favor of just one or two causes, is unconvincing on both empirical and conceptual grounds (Barker and Wilson 2010; more generally, see Beatty 1997).

A second problem for narrow cause views of evolving lineages concerns not their appeals to causes, but rather how they often characterize similarity as effect. The characterization should be more comprehensive, to better fit the idea that lineages are active, dynamic things. This problem requires more introduction than the first because it is easy to misunderstand both it and the involved appeals to similarity more generally. It is not that appeals to similarity in such contexts are dubious in the same way as presumed by many attacks on species essentialism in biology.

To explain this, consider how the type of similarity most disparaged in attacks on species essentialism differ from the population level similarities at issue here. The attacked species essentialist views imply that conspecific organisms are conspecific (at least partly) in virtue of each possessing particular intrinsic traits that organisms of other species lack (e.g., Devitt 2008; Caplan 1980; Kitts and Kitts 1979). Those similarities are trait-particular at the organism level.

\footnotetext{
${ }^{15}$ Templeton's CSC may count as an important exception, depending on how you classify the causes he recognizes within the constituting cause-and-effect pattern.
} 
The essentialists might say, for example, that organisms within the Damaraland mole-rat species (Fukomys damarensis) are conspecific with each other partly because each of them has some distinguishing set of genes, $G$. They would thereby imply that an organism without $G$ wouldn't be conspecific with the organisms of that species.

Advocates of narrow cause views of evolving lineages, on the other hand, would not need to tie conspecificity for the mole-rats to $G$ in particular. This is trivially so for any advocate who denies reference to trait similarities when saying what constitutes conspecificity, as Mayr intended when explicitly keeping reference to similarity effects out of his definition of 'species' (Barker 2010, 76-79). But even if advocates decided the definition should now explicitly refer to these similarities in addition to their causes, they would not thereby tie conspecificity, or lineage identity, to particular intrinsic traits of organisms. Because the similarities they discuss are of the population sort described above, they would merely be implying that - to put it roughlypopulations belonging to the same lineage are more similar to each other than any is to out-group populations, allowing that the particular traits in terms of which this is true change over time without affecting conspecificity or lineage identity. In the Damaraland mole-rat perhaps it is partly in terms of $G$ that such population level similarity holds now, but thousands of generations into the future this sharing of $G$ could evolve away, with the population level similarity that helps distinguish the species then holding in terms of some newer traits. Such similarity is, at the organism level, trait-neutral rather than trait-particular.16

But once the relevant population level trait similarities are vindicated in this way, there is reason to view them in a broader or more comprehensive way than is typical - as more than mere effects, and rather as themselves causal as well. Minimally, and as elaborated below, it seems that two populations having trait frequencies more similar to each other than to a third population can help cause those two populations to be more similar than the third at a later time. This might clarify or better capture what researchers have been thinking when describing evolving lineages as active, dynamic entities in their own right. It is hard to see an evolving lineage as a dynamic cohering entity, persisting continuously through time, if it amounts to just fits and starts of other causes independently producing this instance of similarity, and then later that instance of similarity, with no further causal linkage between such similarity effects. Recognizing the causal status of similarities may show them to be among the linkages and suggest how to uncover other linkages as well. ${ }^{17}$ Put differently, we should see whether bringing appeals to similarity further in line with the more dynamic views of lineages to which they have sometimes seemed opposed might, ironically, improve both-perhaps even unify them in a sense.

\subsection{Problems associating with non-cause-focused ontological species concepts}

In contrast to the cause-focused concepts, non-cause-focused species concepts define 'species' without privileging particular causes. Main examples are versions of the evolutionary species concept (EvSC, Simpson 1961; Wiley 1981; Mayden 1997; Wiley and Mayden 2000) and Kevin

\footnotetext{
${ }^{16}$ Perhaps if proponents of narrow cause views better saw how this shields them from pointed attacks on species essentialism that are based on evolutionary considerations, they would be less reluctant to appeal to both causes and effects in their definitions.

${ }^{17}$ Elliott Sober (1980) famously made a similar clarification about populations. He argued that an important innovation in evolutionary thinking about them was recognizing that trait patterns at the population level at one time can help causally explain population level trait patterns at later times. I am suggesting we extend this idea from the population level to the metapopulation level, though with the appropriate modifications for this different level.
} 
de Queiroz's general lineage concept (1998), which he later refined into the unified species concept (2005a). 18

Proponents of these seem to have two main reasons for keeping causes out of the definitions. First, they appreciate that narrow cause views are too narrow, and so they respond in a particular way: be permissive about which causes are relevant, to the point of not appealing to them in the definitions at all (e.g., de Queiroz 2005a). Second, they think the sense in which species are cohesive evolving lineages is not emphasized enough (or in the right way) in cause-focused counterparts, and so they make this the central piece of their characterizations of species. G. G. Simpson, for instance, says such a lineage is one that evolves "separately from others and with its own unitary role and tendencies" (Simpson 1961, 153). Ed Wiley and Richard Mayden say such a lineage has its "own independent evolutionary fate and historical tendencies" (2000, 73). de Queiroz implies that an evolving lineage is an ancestor-descendent sequence at the metapopulation level, with this comprising "connected subpopulations" (2005b, 6601). These descriptions are deliberately broad, attempting to encompass the variety of ways in which a metapopulation can be a cohesive evolving lineage. Hence, I call them encompassing views of evolving lineages.

Critics have long noted these views are vague and ambiguous: too inexact (Ghiselin 1987; Pigliucci 2003; Richards 2010; and see references in de Queiroz 1998, 69). But dividing this criticism in two helps clarify things.

Suppose momentarily that these views are reasonable in not appealing to specific causal variables when describing what constitutes an evolving lineage. Are they thus appealing to just some sort of lineage cohesion? If so, it seems like cohesion in a different sense than the trait similarity sense of cohesion that we saw implicated in narrow cause views. Instead, encompassing views seem to follow the lead of Hull's seminal work (e.g., 1976) which, as Neto (2016) and others have emphasized, uses 'cohesion' to capture how lineages are spatiotemporally continuous wholes. This has also been described as a kind of integration or connectivity between populations within a lineage (Mishler and Brandon 1987; Ereshefsky 1991; Wilson 1999; Ereshefsky 2001; Barker and Wilson 2010). Even if such integrative cohesion sometimes involves similarities, it is also in a sense over and above them. Rather than an effect variable within a cause-and-effect pattern associated with lineages, it is more like the overall pattern itself, or a state of the whole metapopulation sustained by the pattern featuring within it. But attempts to articulate this are quite underdeveloped, leading to unacceptable implications. Implying that a metapopulation features such integrative cohesion when conditions of "unitary role" or "historical tendencies" or "connection between subpopulations" are satisfied is not exact enough about those conditions to rule out some things that clearly should not count as evolving lineages (Pigliucci 2003).

Although I will refer to this inexactness problem as afflicting appeals to integrative cohesion, the nub of it remains even if proponents resist talking in terms of such cohesion. Sticking instead, for example, with the EvSC's terms, many populations or subpopulations may be said to manifest some unitary role, or display some historical tendencies, even though they are not evolving lineages. Switching to the terms of the GLC and USC, it is harder to tell whether nonevolving lineages will satisfy the conditions, because the conditions are even less clear. What conditions give the implicated type of ancestor-descendent sequence its identity, setting it apart as a sequence numerically distinct from others, or what conditions make a thing a separate ancestor or descendent within such a sequence? 19

\footnotetext{
${ }^{18}$ For discussion of similarities between de Queiroz's concepts and EvSCs, see Naomi (2011) and Mayden (2013).

${ }^{19}$ Some researchers have tried to defend against this problem by treating it as a problem for epistemological lineage detection, rather than for the ontological views implied (de Queiroz 1998, 70; Zachos 2016, 107-8). This
} 
The second problem of inexactness for encompassing views is about causes rather than integrative cohesion or its analogues.20 These views are inexact about causes because they imply we should not appeal to causes when specifying the conditions for being an evolving lineage. ${ }^{21}$ As a reaction to the problems for cause-focused views, this is an overreaction. Although biological systems are too varied and complex to expect one or a small set of causes to be "most important" in all cases of evolving lineage formation or maintenance, they are not so chaotic that anything goes. If we think at least some significant number of (surely not all) evolving lineages are clearly distinct from other sorts of things, we have prima facie reason to think there will be some recurring patterns involving causal variables (probably many and involving complex interactions) that help make these lineages distinct. Acknowledging that we have far to go on this part of a theory of evolving lineage constitution would thus be better than a priori ruling out appeals to causes from the start. The lesson should be: look for complex causal patterns, rather than simple ones and rather than not looking at all.

\section{Learning from Existing Views}

Despite their problems, the views of evolving lineages that underlie ontological species concepts also have strengths. To help learn what to aim for in a theory of evolving lineage constitution, Table 11 shows both the strengths of existing views and lessons gleaned from their problems. From the contents of that table, the next table, Table 2, then infers desiderata that a new theory of evolving lineage constitution should meet and provides a synoptic preview of how the feedback theory will meet those desiderata.

We see that we should get more comprehensive than narrow cause views of evolving lineages, while also more exact than encompassing views. Steered by this guidance, the next two sections introduce key ideas the feedback theory employs for meeting the desiderata. Based on these, Section 8 then formulates constitutive conditions for being an evolving lineage.

\section{Feedback in Evolving Lineages}

First we get more comprehensive about causal variables, then about similarity.

\subsection{Uncovering the relevance of feedback relations}

It is not just that multiple causal variables, rather than just one or two, often importantly interact to produce similarity at the population level. If we take a long enough view of lineages, these variables seem mutually reinforcing over time. The key starting idea is to recognize much more specifically that this is, perhaps often, feedback. ${ }^{22}$ Not feedback in a loose or metaphorical sense, but rather in a literal and technical sense that is dynamically modeled in parts of engineering,

mistakes the problem. The problem is that the ontological conditions for being an evolving lineage are so inexactly specified that many non-evolving lineages might satisfy them — or at least we can't rule this out and the nature of evolving lineages hasn't been illuminated-even if our detection methods were perfect and told us of every trait and every interaction of all organisms and populations. In such a fanciful case, we still wouldn't know which of the exhaustively accounted conditions are the ones that make a thing an evolving lineage.

${ }^{20}$ Henceforth, take the "or its analogues" qualification on such reference to integrative cohesion as implied.

${ }^{21}$ This implication is perhaps clearest in de Queiroz (2005a).

${ }^{22}$ This starting idea has some affinities with homeostatic property cluster (HPC) interpretations of theories in biology about species taxa (e.g., Boyd 1999), and I was led to it after helping develop one of those interpretations (Wilson, Barker, and Brigandt 2007). But the starting idea about feedback goes beyond those interpretations, and the fuller feedback theory proposed below departs from them sharply. Boyd's original HPC interpretation

○ OPEN ACCESS - PTPBIO.ORG 


\begin{tabular}{lll}
\hline & Strengths & Lessons from Problems \\
\hline $\begin{array}{l}\text { Narrow } \\
\text { cause } \\
\text { views }\end{array}$ & $\begin{array}{l}\text { Appeal to exactly specified causal } \\
\text { variables underlying evolving } \\
\text { lineages. } \\
\text { Appeal to exactly specified effect } \\
\text { variables underlying evolving } \\
\text { lineages. }\end{array}$ & $\begin{array}{l}\text { Should appeal to more comprehensive set of causal } \\
\text { variables, to capture important patterns of } \\
\text { interaction. }\end{array}$ \\
$\begin{array}{l}\text { Should investigate the potential causal status of } \\
\text { some similarity effect variables. }\end{array}$ \\
$\begin{array}{l}\text { Encom- } \\
\text { passing } \\
\text { views }\end{array}$ & $\begin{array}{l}\text { of evolving lineages. } \\
\text { Appreciate the involvement and } \\
\text { complexities of many causal } \\
\text { variables. }\end{array}$ & $\begin{array}{l}\text { Should attempt to be more exact about what } \\
\text { integrative cohesion or relevant types of it involve. } \\
\text { Sariables rather than excluding appeal to them. }\end{array}$ \\
\hline
\end{tabular}

Table 1: Strengths and Lessons from Existing Views.

biochemistry, physics, and so on. 3 Instantiations or increases in the value of some causal vari-

proposes that a species taxon is constituted by a set of properties that imperfectly cluster together, plus mechanisms underlying the cluster $(1999,143)$. No one of the properties or mechanisms is strictly necessary for a group of populations to be a species, nonetheless these tend to "co-occur" $(1999,143)$. Similarly, I will suggest multiple causal variables are relevant, without insisting on the necessity of any one of them. A first difference clarifies upon seeing that Boyd and I mean different things by properties and mechanisms vs. causal variables. By causal variables I mean kinds of events, which are diachronic. By properties, and perhaps mechanisms (though not their operation), he seems to imply synchronic dispositions, traits, capacities and so on. One sign that this difference is significant is that it is part of Boyd's claiming that species taxa are literally natural kinds, whereas I propose many of them are literally feedback systems. Now it may be that they are both: although Boyd does not discuss feedback systems, he does entertain the idea that a species taxon is both a kind and an individual, and he may count feedback systems as individuals (among other things) (1999, 163). I am inclined to some version of such liberalism too, and will clarify and maintain in my proposal an important role for (at least some of) the similarity relations that Boyd argues (1999, 165-69) are important. However, it is not clear how liberal Boyd is in the end, as he suggests his kinds view is "opposed" to the view that species are "natural individuals" $(1999,167)$. A second and more biologically relevant difference is that Boyd does not focus on dynamic feedback relations in particular. He writes in much more general terms - of some cluster properties "favor[ing] the presence" of others, and underlying mechanisms also "tend[ing] to maintain the presence" of cluster properties (143). Those relationships can be realized in a variety of ways, without involving literal feedback at all. In contrast, feedback relations and details about them will below become central to my proposal, especially in the articulation of a special kind of cohesion. This difference is to be expected because Boyd was primarily addressing the metaphysical status of species rather than trying to break new ground on the evolving lineage problem. The HPC interpretation by Wilson et al. implicitly hints at a role for feedback relations $(2007,199-200)$, but like Boyd's does not single them out as such nor elaborate on them as the centerpiece of a proposal about the constitution of evolving lineages.

${ }^{23}$ In addition to the termite example already given, there is well-known focus on feedback relations in some other areas of biology, where metapopulation evolving lineages are not the object of study. Consider chemotaxis networks in bacterial navigation (e.g., Wadhams and Armitage 2004) and both ecological (e.g., Miao et al. 2017) and eco-evolutionary dynamics in communities (e.g., Becks et al. 2012). Closer to the present topic, there is a long though relatively spotty history, beginning with Darwin (Robertson and Grant 1996a, 10) and leading up through Fisher (1930) and others to some contemporary researchers (e.g., Caporale and Doyle 2013; Lehtonen and Kokko 2012; Robertson and Grant 1996a, 1996b), of claiming that feedback relations are important to understanding natural selection within a population. But the present topic of evolving lineages is about metapopulations, about connections between populations that help set certain metapopulations apart from others as species or other evolving lineages. Although related, these two topics are quite distinct when it comes to constitution problems and providing theoretical definitions of the related concepts. On the former topic, where feedback relations have periodically been deemed important, the target concepts are NATURAL SELECTION and POPULATION; on the latter, where the 
Desiderata

1. Aim for relatively exact appeals to causal variables that more comprehensively capture their relevant interactions.

2. Aim for relatively exact appeals to trait similarity variables that more comprehensively capture their status as causes, in addition to effects.

3. Aim for emphasis of integrative cohesion that more exactly specifies what this is.

4. Aim to be more exact about how causal variables are involved in integrative cohesion.
How Feedback Theory Will Meet Desiderata

Do this by proposing roles of feedback relations between causal variables forming a metapopulation feedback system.

Do this by accommodating variable $t$ as both a cause and effect variable within metapopulation feedback systems, thereby motivating a shift in focus from cohesion as unique effect variable inside a lineage system, to cohesion as an overall integration of the whole system.

Do this by specifying integrative cohesion as metapopulation feedback cohesion, $M$, a property of metapopulation feedback systems.

Do this by proposing that $M$ varies with the frequencies and magnitudes of feedback relations between variables in the metapopulation feedback system.

Table 2: Desiderata for a Theory of Evolving Lineage Constitution. (Desiderata numbers do not indicate relative importance within the list.)

ables at one time help produce subsequent instantiation or increase in those same causal variables. The causal variables now feed into the same causal variables later, just as a turbo engine's operation at one time produces output that feeds back into and amplifies its subsequent operation. This can internally drive a metapopulation to persist as a lineage against forces that threaten its overall coherence. It can also explain why sometimes the coherence is nonetheless lost, as, for example, the threatening forces overwhelm the feedback relations, pushing the lineage over a tipping point.

To clarify feedback between causal variables, consider Table 3. It lists and labels some of the variables that authors have (explicitly or implicitly) appealed to when discussing how populations within a species cohere, especially in the sense of how they are homogenized or become relatively trait-similar at the population level.

Some of the variables in Table 3 will have more restricted relevance than others. Variable $r$, for instance, will not apply for many metapopulations of asexuals. Also, the list is provisional and surely incomplete. Experience suggests we will change the list. Empirical and conceptual

importance of feedback relations are here emphasized, they instead include EVOLVING METAPOPULATION LINEAGE and SPECIES. I have yet to find anybody claiming particular feedback relations are part of what constitutes evolving lineages, or that such lineages literally are feedback systems, or that definitions of concepts such as sPECIEs should be given in terms of feedback relations. Celso Neto entertains the importance of feedback relations when discussing species cohesion, though in the more traditional terms of feedback relations within a single population; he says "feedback relations between organisms and environment occur locally, usually on one geographic population" (Neto 2016, 144). 


\begin{tabular}{|c|c|c|c|}
\hline $\begin{array}{l}\text { Variable } \\
\text { label }\end{array}$ & $\begin{array}{l}\text { Name of } \\
\text { variable }\end{array}$ & Description of action & $\begin{array}{l}\text { Example works appealing } \\
\text { to variables }\end{array}$ \\
\hline$g$ & $\begin{array}{l}\text { Gene } \\
\text { flow }\end{array}$ & $\begin{array}{l}\text { Transmission of genes from one population to } \\
\text { another (e.g., via migration) can help cause } \\
\text { trait similarities between them. }\end{array}$ & $\begin{array}{l}\text { Mayr 1970; Brooks and } \\
\text { Wiley 1988; Morjan and } \\
\text { Rieseberg } 2004\end{array}$ \\
\hline$s$ & $\begin{array}{l}\text { Shared } \\
\text { selection } \\
\text { regimes }\end{array}$ & $\begin{array}{l}\text { Populations sharing selection regimes can help } \\
\text { cause trait similarities between them. }\end{array}$ & $\begin{array}{l}\text { Ehrlich and Raven 1969; } \\
\text { Van Valen 1976; Lande } \\
\text { 1980; Mishler and } \\
\text { Donoghue 1982; } \\
\text { Templeton 1989; Cohan } \\
2011\end{array}$ \\
\hline$h$ & $\begin{array}{l}\text { Homeo- } \\
\text { static } \\
\text { develop- } \\
\text { mental } \\
\text { systems }\end{array}$ & $\begin{array}{l}\text { Shared mechanisms of developmental } \\
\text { homeostasis between populations can help } \\
\text { causally sustain or increase trait similarities } \\
\text { between them. }\end{array}$ & $\begin{array}{l}\text { Ehrlich and Raven 1969; } \\
\text { Mayr 1970; Wiley } 1981\end{array}$ \\
\hline$c$ & $\begin{array}{l}\text { Colo- } \\
\text { nization }\end{array}$ & $\begin{array}{l}\text { When a representative off-shoot of a } \\
\text { population colonizes a new area, creating a new } \\
\text { population, this can causally account for some } \\
\text { later trait similarities between them. }\end{array}$ & $\begin{array}{l}\text { Hellberg et al. 2002, } \\
275-77\end{array}$ \\
\hline$m$ & $\begin{array}{l}\text { Muta- } \\
\text { tion }\end{array}$ & $\begin{array}{l}\text { When mutations are adaptive this can help } \\
\text { them spread across populations, contributing } \\
\text { to trait similarities between them. }\end{array}$ & $\begin{array}{l}\text { Mayr 1970; Hellberg et } \\
\text { al. 2002, 275-77; Morjan } \\
\text { and Rieseberg } 2004\end{array}$ \\
\hline$r$ & $\begin{array}{l}\text { Genetic } \\
\text { recombi- } \\
\text { nation }\end{array}$ & $\begin{array}{l}\text { When opportunities for genetic recombination } \\
\text { within a genotype are restricted to certain } \\
\text { populations this can help sustain or increase } \\
\text { trait similarities between them (relative to } \\
\text { out-group populations). }\end{array}$ & Carson 1957; Mayr 1970 \\
\hline$t$ & $\begin{array}{l}\text { Trait } \\
\text { similari- } \\
\text { ties }\end{array}$ & $\begin{array}{l}\text { Trait similarities between populations at one } \\
\text { time can help lead to trait similarities at a later } \\
\text { time. }\end{array}$ & To be discussed here. \\
\hline
\end{tabular}

Table 3: Provisional Running List of Causal Variables

work will recommend further specifying some variables. ${ }^{24}$ Others may be replaced.25 Some, presently unappreciated, will be added. But the overall system of causal variables can survive these changes, with our understanding sometimes improving because of those changes.

\footnotetext{
${ }^{24}$ For instance, although authors often cite gene flow as an important cause of cohesion in at least the trait similarity sense (e.g., Mayr 1963; Morjan and Rieseberg 2004), they have long had more specific types of gene flow in mind. These include instances of promotional gene flow that help homogenize populations by spreading adaptive genes between them (Mayr 1970, 289, 300), and preventative gene flow that makes divergence between populations less likely by "damping the occurrence of change within local populations" (Ereshefsky 2001, 115; also see Mayr 1970, 168-69). A more recent example: transmission in bacteria of "niche-transcending genes", which sometimes helps homogenize groups of bacteria, but other times has the opposite effect (Cohan 2011).

${ }^{25}$ Given the examples in the previous footnote, perhaps $g$ will later be replaced with a suite of more specific gene flow variables; different types of shared selection regimes are recognized, including stabilizing and direction regimes; and so on.
} 
The feedback theory predicts that feedback relations between at least some of the variables in Table 3-both between different variables and between earlier and later instances or values of the same variable - are often important for helping homogenize populations. To illustrate, consider the species Alcantarea imperialis, a diploid, perennial, and outcrossing Bromeliad plant. Two of its populations, $A$ and $B$, reside about $100 \mathrm{~km}$ apart in Brazil's Atlantic Rainforest (Barbará et al. 2007). ${ }^{26}$ Pollination is mediated primarily by bats and predicts relatively high levels of gene flow between the populations (Barbará et al. 2007, 1989; I. Sazima, Vogel, and Sazima 1989; M. Sazima, Buzato, and Sazima 1999). But measures suggest actual gene flow has been surprisingly low, $<1 N_{e} m$ (Barbará et al. 2007). Also, the plant's rosettes and bracts are often red or purple but a green colour morph has arisen in population $A$ (Barbará et al. 2008). Suppose selection for the green morph becomes very strong and when this is combined, at time $t_{1}$, with the very little gene flow that exists between $A$ and $B$, this is enough for the green morph to begin spreading through population $B$ as well. The adaptation involves bats strongly preferring the green plants, and mediating pollination more frequently than before. This in turn helps cause an increase in gene flow from $B$ to $A$ at a later time, $t_{2}$. Thus instances of the causal variables $g$ and $s$ at $t_{1}$ help cause later instances of $g$ and $s$ at $t_{2}$.

This example may sound like a case of positive feedback. Positive feedback is often thought of as disruptive or destabilizing, while negative feedback is considered a stabilizer. But neither is always the case (Robertson and Grant 1996a). Also, what counts as stabilizing or destabilizing depends on reference frame. Seeing the feedback in the Alcantarea imperialis example as destabilizing is probably to use the initial values of $g$ and $s$ and the red and purple color traits as reference frame. Relative to those, the feedback relations then hasten the system's movement to different states, e.g., to higher rates of gene flow and to new selection for the green trait. But with, instead, the integration of populations $A$ and $B$ as the frame of reference, the feedback seems less disruptive and rather contributing. And on either frame of reference, the feedback relations seem important to changes of state in the metapopulation, changes that may seem at first to threaten homogenization within the metapopulation, but which end up promoting it through feedback.

There is no claim that causal variables at one time always help bring about later instances of causal variables. Indeed, sometimes an interaction of $g$ and $s$ at one time help diminish $g$ and $s$ at a later time. In bacteria in a Yellowstone hot spring, for instance, gene flow (via processes such as lateral gene transfer) and selection at one time seem to have helped spread the genetic control for a nitrogen fixing pathway between two populations; the shared pathway then was leveraged in different ways by the two populations, helping them adapt divergently to different thermal and nutrient zones, which in turn later diminished values of $g$ and $s$ between them (Cohan 2011, 57). But such examples indicate that negative feedback, in addition to positive feedback, is sometimes important within metapopulations, and in fields where feedback relations are given more attention the interactions between both positive and negative feedback are also modeled (e.g., Ausborn, Wolf, and Stein 2009; Pfeuty and Kaneko 2009; Banerjee and Bose 2008). So, on one hand, the feedback theory of evolving lineages does predict feedback relations are important to homogenizing populations, and in ways that help sustain the metapopulations they form as evolving lineages distinct from one another-there is nothing remarkable about the described Alcantarea imperialis scenario, it seems routine. On the other hand, further investigation of negative feedback and feedback interactions may lead the theory to also predict upper limits to homogenization that help sustain metapopulations as evolving lineages from the other direction-preventing their constituent populations from fusing into one vast population, to which the prefix 'meta' would no longer apply. Such predictions would motivate the search

\footnotetext{
${ }^{26}$ Let $A$ be the population that in the cited papers is labelled IJF, and let $B$ be the population labelled IMC.
} 
not just for tipping points but also sorts of bi-stability that are familiar in some feedback systems in other fields, and which would help further underwrite the individuality commonly attributed to evolving lineages.

\subsection{Trait similarity is just another variable in the system}

To next get more comprehensive about similarity, the key idea is to recognize how some forms of trait similarity, though typically treated as an effect variable, are probably often causal as well, and enter into feedback relations within feedback systems, just like other variables.27

How can trait similarity cause things? Consider three of the Baltic Sea populations of willow warbler (Phylloscopus trochilus) sampled by Bensch et al. (2009): one in Finland, one straddling the Sweden-Finland border, and one in central Sweden. Let these be $A, B$, and $C$, respectively. ${ }^{28}$ It is known that birds in $A$ and $B$, belonging to the $P$. $t$. acredula sub-species, tend to migrate south east towards southern Africa, adaptively avoiding geographic obstacles. But many birds in $C$ are instead hybrid crosses, resulting from matings between $P$. t. acredula and another sub-species, $P$. t. trochilus, which displays different adaptive migration behaviors. The hybrid $C$ population is small and poorly adapted compared to the others. It is hypothesized that many birds in $C$ show deleterious migration behavior, rather than the adaptive migration behaviors of, for example, most birds in $A$ and $B$ (Irwin 2009). Studies suggest these behaviors are under strong genetic control (Pulido 2007). Simplistically, but harmlessly for illustrative purposes, let us recognize $G$ as the genomic trait made up of the genetic contributions to the adaptive migration behaviors typical in populations $A$ and $B$. So, the frequency of adaptive trait $G$ will be relatively high in both $A$ and $B$, and low in $C$. Suppose that at a time, $t_{1}$, these frequencies are $90 \%$ in $A, 91 \%$ in $B$, and just 3\% in poorly adapted $C$. Next the three populations face a shared selective pressure: winter's arrival. They respond by migrating. The relatively many birds with trait $G$ in populations $A$ and $B$ tend to fare better than the few birds in those populations who lack $G$ and follow more challenging migration routes. Consequently, by time $t_{2}$ suppose that $G$ has increased in frequency to $91 \%$ in $A$, and $92 \%$ in $B$. In contrast, $G$ falls to $2 \%$ in $C$ over the same time period, $t_{1}-t_{2}$, due to the sorts of stochastic affects that often influence populations of such small size. And from $t_{2}$ to a later time, $t_{3}$, this trend continues: $G$ rises to $92 \%$ in $A$ and $93 \%$ in $B$, and falls to $1 \%$ in $C$.

In this example we can view a kind of trait response similarity as among important causes.29 One event occurring over period $t_{1}-t_{2}$ is the $G$ trait frequency in population $A$ responding in a way similar to $B$ 's. This, like many types of similarity, is relative-in this case relative to $C$ 's response. More exactly, the $G$ trait frequency responses of populations $A$ and $B$ during $t_{1}-t_{2}$ are much more similar to each other than either's is to $C$ 's. Moreover, there is another event of this type at the later period $t_{2}-t_{3}$, where again $A$ and $B$ respond more similarly to each other than either does relative to $C$. And we can say that the first of these events is one of the contributing causes of the second: part of the reason that the responses in $A$ and $B$ over the later time period are much more similar to each other than either is to response in $C$, is that the responses between $A$ and $B$ were much more similar to each other than to $C$ during the preceding time period as well.

\footnotetext{
${ }^{27}$ There is some disagreement between metaphysicians focusing on causation, about what kinds of things can be causes. Some argue that only events can be causes, others argue that facts can be causes, and so on (Schaffer 2016). I assume that claims of the form "trait similarity, $t$, causes $X$ " can be translated into the language of any of these competing views. For example, if only events are causes, then the translation would be something like "event $E$ causes $X$ in virtue of the trait similarity, $t$, involved in $E "$.

${ }^{28}$ Bensch et al. represent these populations in their Table 2 using different letters for labels.

${ }^{29}$ In more general terms Barker and Wilson (2010) highlight this type of similarity, though not its causal status.
} 
Similar examples could also show how trait similarities (values of variable $t$ ) over one period can help increase other causal variables at later periods. When two populations $A$ and $B$ are more similar to each other in various respects than either is to $C$, this can help lead to more gene flow between $A$ and $B$ than between either of those and $C$, for example. And here the feedback theory again predicts such feedback is common and important within lineages, not merely possible.

Figure 2(c) puts together this section's two key ideas-the relevance of feedback relations, and population level trait similarity being yet another variable that is both cause and effect-and contrasts them against two existing views. One of these, in figure 2(a), is an example narrow cause view, one that underlies Mayr's BSC; the other, in figure 2(b), is an existing alternative to such narrow cause views. Although that alternative, articulated in Barker and Wilson (2010), is more comprehensive about causes than narrow cause views, it retains from them the idea that trait similarity is just an effect variable. 30

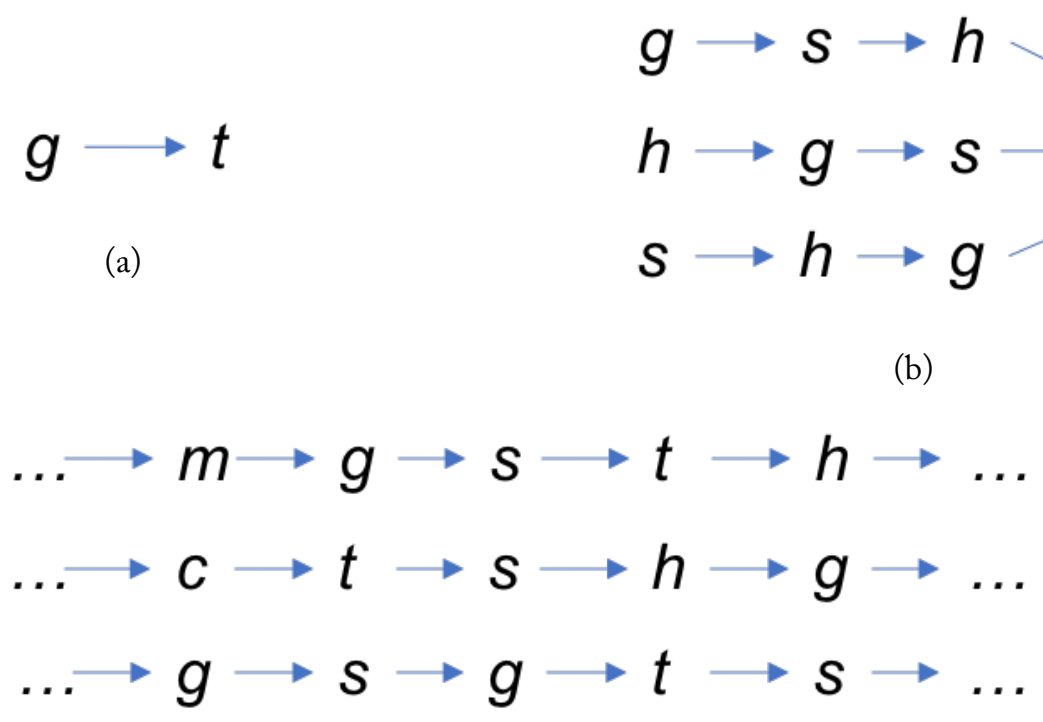

(c)

Figure 2: Three-way Comparison of Views of Evolving Lineages. 2(a) is an example narrow cause view. 2(b) is an existing alternative to narrow cause views (found in Barker and Wilson 2010). 2(c) combines some of the ideas so far proposed here as part of the feedback theory.

One way to see that the more comprehensive view depicted in figure 2(c) fits better with the familiar idea that evolving lineages are dynamic, persisting things, is to consider how it removes the motivation for thinking - as we saw Mayr did and others do-that the relevant question for a species concept to answer is: what are the main causes of persisting trait similarities between conspecific populations? Because similarity is now a variable just like all the others, and feedback relations feature between these, all those variables are effect variables in addition to causal variables. There is no reason to single out similarity as a special effect whose causes we should enshrine within a definition of 'species' or other evolving lineage terms. Indeed, no one of the variables is a priori more special than the others, as either cause or effect. Accordingly we should change the very form of what we think is the relevant question. It is not about seeking the most important causes of this or that effect, but rather about which suite of variables are most prominent as both causes and effects entering feedback relations that constitute a dynamic

\footnotetext{
${ }^{30}$ See especially figure 5 in Barker and Wilson (2010).
} 
and persisting lineage system. We do not fix on one very specific causal relation that occurs in fits and starts. We focus on whole lineage systems that cycle through feedback relations holding integratively between a variety of variables, perhaps uncovering tipping points, bi-stability, and other features of feedback systems.

In abstract terms this may seem a shift to a more bird's eye view of evolving lineages: instead of emphasizing a kind of cohesion that is a trait similarity effect variable inside a lineage system, we ascend to view the system as a whole, where its overall integration comes into focus. We saw that encompassing views of such lineages have attempted to initiate a similar shift, but without being exact enough about both the implicated system-wide integrative cohesion, and the role of causal variables within it. That inexactness has left the idea that evolving lineages are dynamic persisting things, at the metapopulation level, vulnerable. Critics have wondered whether such higher-level things are illusory in a way-whether they appear to themselves be biological entities doing things, when really they are epiphenomenal artifacts or signals trickling up to the metapopulation level from causal processes happening strictly at lower levels (e.g., Cracraft 1989b; Wilkins 2018).

But further conceptualizing the roles of feedback relations being proposed here will allow us to be more exact than encompassing views. As a feedback system, one of the things an evolving lineage would do is contribute to its own dynamic continuation and changes of state. ${ }^{31}$ This is seen in other feedback systems, whether a termite's mound or a turbo engine. Take the feedback out of those and the quantitative and qualitative differences would be profound.

\section{Metapopulation Feedback Cohesion and Variable Spaces for Depicting It}

To get more exact than encompassing views about both integrative cohesion and how causes are involved in it, consider two key ideas. One is viewing an evolving lineage as a metapopulation feedback system whose integrative cohesion is a specific type of diachronic cohesion of the overall system, often coming in various and fluctuating degrees or intensities. The other idea is that feedback relations between the identified causal variables within the system are what realize (or implement) this cohesion, while its fluctuating degree or intensity is a function of the frequencies and magnitudes of those feedback relations.

To spell out these ideas, first let 'metapopulation feedback system' refer to any metapopulation featuring recurring causal variables of the sorts described above (e.g., table 3), and wherein values for these variables sometimes feed back into later values of those variables.

These systems can vary in at least two ways. The values of their variables can range in magnitude, and the feedback relations between variables can range in frequency. When a metapopulation features both relatively high frequencies and magnitudes, let us say it has a high degree of metapopulation feedback cohesion, or $M$. When a metapopulation features relatively low frequencies and magnitudes, it features low $M$. More mixed or intermediate frequencies and magnitudes correspond to intermediate $M$ values. So $M$ represents a property (or state) that a metapopulation can have over some time period(s) and which can vary by degree. Thus $M$ is essentially diachronic, not synchronic, even if particular ways of representing it sometimes conceal this.

Perhaps the ideal way to determine values of $M$ involves repeated interventional (experimental) testing to detect frequencies and magnitudes of feedback relations with relatively exacting precision. But that will often be practically impossible. Rather than speculate here on practically

\footnotetext{
${ }^{31}$ This is not to deny that components of the feedback relations at the metapopulation level are materially determined by lower level entities and relations and activities. Materialism and recognition of higher level processes go together (Sober 1980, 1999).
} 
superior means of detection, I want to use simplified variable spaces to show how mathematical and visual means of indirectly depicting $M$ values can help with clarifying and stating conditions for being an evolving lineage. Here I am inspired by Godfrey-Smith (2009), who has shown how powerful this approach can be in the different context of theorizing about what constitutes natural selection within a single population. 32 In addition to addressing a different biological system, Godfrey-Smith was not discussing feedback relations in particular. But more generally he was, as I am, trying to investigate constitutive conditions in a system where relevant variables are both continuous and complexly related. His simplified variable spaces proved much more suited to and insightful for this than more traditional methods from philosophy (Sterelny 2011, 489-90). Perhaps more ambitiously than Godfrey-Smith, I will try to show how clumping in such a space (over time) can be precisely characterized, though the truth or falsity of the main ideas in the feedback theory do not depend on this particular way of expressing them. 33

Start with just one variable, $g$, a time period $t_{1}-t_{2}$ that spans several generations, and two populations, $A$ and $B$. During $t_{1}-t_{2}$, there will be some number of generations ( 0 or greater) in which genes flowed from $A$ to $B$, and some number for flow from $B$ to $A$. We can take the average of those numbers as the frequency component of $g$. The flow of genes in a generation from $A$ to $B$ will also have a magnitude, e.g., one measured by the proportion of migrants involved in the process. Likewise in the direction from $B$ to $A$. The average of these two magnitudes can serve as the magnitude component of $g$. We can then choose a mathematical operation that multiplies the frequency component and magnitude component so that all results of this are scaled between 0 and 1 . Applying this operation here would give an overall value for $g$ in our example of populations $A$ and $B$ over $t_{1}-t_{2}$.

Metapopulations often contain more than two populations. To figure $g$ for such metapopulations, we can average over the $g$ values for each possible pairing of populations in the metapopulation.

Suppose we can similarly capture the frequency and magnitude of the other causal variables occurring within metapopulation feedback systems. For a metapopulation we can then arrive at values between 0 and 1 for each of those variables additional to $g$. For illustrative purposes, figure 3 represents just two variables in addition to $g$, and features the three of these as axes of a three-dimensional variable space. We could then plot the location of metapopulations in this space. Their locations represent their respective $M$ values, in what we can call an $M$ space.

\section{Conditions for Being an Evolving Lineage}

If we propose $M$ as the specification of the integrative cohesion that we saw is discussed by some authors, how should we use this and the aid of variable spaces to help address the evolving lineage problem?

First consider that the number of metapopulations that are mere candidates, in the most minimal sense, for being evolving lineages is massive. Any $n$-tuple of any populations is a candidate, including the $n$-tuple consisting of a particular bacterial population on my apple and a slug population on the island of Montreal. ${ }^{34}$ Given this, and representing $M$ values via $(g, s, t)$

\footnotetext{
${ }^{32}$ Biologists Queller and Strassmann (2009) use a similar strategy on the topic of what constitutes being an organism.

${ }^{33}$ To be as useful as possible, variable space expression will need to sort through various methodological decisions and adopt conventions about how best to relate measures of different variables. But that sort of fine grained and technical work is significantly downstream of this paper, which instead is offering the prior conceptual clarifications and motivation for that further work.

${ }^{34} \mathrm{I}$ set aside whether an $n$-tuple of populations is a candidate when $n=1$.
} 


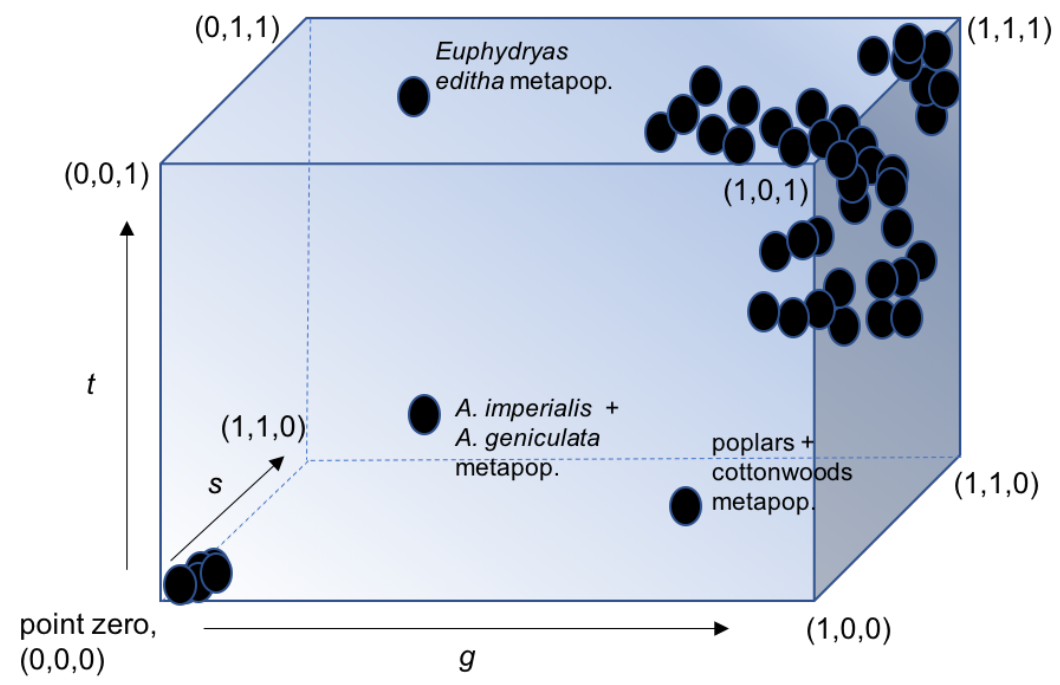

Figure 3: Plotting $M$ Values for metapopulations in $M$ Space. Black ovals represent metapopulations. Many will cluster near point zero, being the poorest candidates for evolving lineages on the feedback theory. The clustering of metapopulations in the back top right region reflects the hypothesis that paradigmatic evolving lineages exist. The location of the Euphydryas editha metapopulation exemplifies the 1969 claim of Ehrlich and Raven that a California metapopulation within this group features very little gene flow between populations, but seemingly high $t$ and $s$. The $A$. imperialis $+A$. geniculata example reflects the implication in Barbará et al. $(2007,1990)$ that sympatric groups from these two named species feature low but non-zero $g, s$, and $t$. The poplars + cottonwoods example is from Templeton (1989) who claimed low levels of $t$ and $s$ for this inter-specific group, despite significant levels of gene flow between the involved poplars and cottonwoods. Design aspects of this figure are taken directly from figure 3.1 and figure 5.1 in Godfrey-Smith (2009).

location in figure 3 s simplified $M$ space, the vast majority of candidate metapopulations will probably have $M$ values at or relatively very near $(0,0,0)$. This is so when adding dimensions to the $M$ space as well. For discussing those more complex spaces as well as simpler ones, let the meeting of axes at the point where all variable values are zero be called point zero. So $(0,0,0)$ is point zero in figure 3. If many species are evolving lineages in some way that sets them apart from other metapopulations, then on the current proposal it is predicted that some relatively small number of candidate metapopulations will form one or more clumps in $M$ space, some distance from point zero. And then there will probably be a grading off between any of those clumps and point zero, representing intermediate cases (cf. Godfrey-Smith 2009 on "Darwinian populations"). This is just to say we should not expect all metapopulations to sort into just two discrete groups, those near point zero and those in one or more other clumps that may represent species or some other relatively clear type of evolving lineage.

Assuming that is the case, there will probably be no sharp line separating evolving lineages from all other metapopulations. It will often be better to talk of degrees. A metapopulation consisting of both Alcantarea imperialis and Alcantarea geniculata Bromeliad populations may, for example, be far enough from point zero (see Barbará et al. 2007, 1990) that we should count it as an evolving lineage to some degree even if it isn't located in a clump that we associate with, say, a species region of the $M$ space in particular. More generally, both the increasing structure that systematists are finding within metapopulations and the surprising extent of evolutionary connectivity between them (Mallet, Besansky, and Hahn 2016) give two large reasons to expect such intermediate cases (or less integrated types) of evolving lineages. 
But this hardly forces us to count any old metapopulation located some distance from point zero as an actively evolving lineage. Even if several sets of conditions are each sufficient in usual contexts for being an evolving lineage, a thing will not be such a lineage without satisfying at least one of those various sets. To capture the popular idea that many evolving lineages are relatively distinct from each other while popping out, to varying degrees, against the noisy backdrop of mere metapopulations, the feedback theory proposes that one of these sufficient sets will contain at least three and perhaps four conditions.

\subsection{First condition: tumbling addition}

To grasp the first condition, start with reverse reasoning: think about ways in which a metapopulation could fail to be a whole evolving lineage according to the feedback theory. One way is to be less than a whole evolving lineage, in virtue of leaving out one or more populations that are sufficiently connected to it by feedback relations. In such a case of failure, at least one population left out is about as connected by feedback relations to the metapopulation's constituent populations as each of them is to each other. Adding such a mistakenly left-out population to the metapopulation would thus diminish its $M$ value little, or not at all, or even raise it. So when a metapopulation does not fail in this way, when it is not mistakenly leaving out a population, it would seem to be satisfying an opposite condition: if any out-group population were added to it, its $M$ value would tumble. 15 If and only if a metapopulation satisfies this tumbling addition condition, the metapopulation averts "less than whole" failure-call it a tumbling addition metapopulation. 36 This is for relations between causal variables within it to be overall of much greater frequency and magnitude than they would be in any more inclusive group that includes that metapopulation plus any other population. What counts as "significant" or "greater"-and so what counts as a tumble in $M$ space rather than, say, a slip-will be a relative matter. For example, if a drop in a metapopulation's $M$ value upon adding any further population is relatively similar to drops seen when adding out-group populations to what are widely deemed paradigmatic evolving lineages in roughly the same region of $M$ space, then this is a reason to count the drop as significant. Conversely, if the drop in $M$ value upon population addition is much smaller than compared to the paradigmatic cases in roughly the same region of $M$ space, that is a reason to not count the drop as significant. 37 And even in these relative or comparative terms, we should not expect sharp lines.

\subsection{Second condition: climbless subtraction}

On the feedback theory, another way for a metapopulation to fail to be a whole evolving lineage is to be more than a whole evolving lineage, by letting in one or more populations that are not sufficiently connected by feedback. ${ }^{38}$ So in such failure, there is at least one constituent population whose omission from the metapopulation would result in that metapopulation's $M$ value

\footnotetext{
${ }^{35}$ This is because all left-out populations in such a case would be rightfully left out: none is sufficiently connected by feedback to the metapopulation, and so addition of any would cause the metapopulation's $M$ value to tumble.

${ }^{36}$ The previous sentence characterized this epistemically, the next does so ontologically.

${ }^{37}$ Seeing that what counts as significant is relative to what is going on with paradigmatic evolving lineages in roughly the same region of $\mathrm{M}$ space also allows the present account to recognize multiple levels of evolving lineages, i.e., evolving lineages at different levels of $M$ space. For instance, it can recognize higher grade and lower grade evolving lineages, where those of higher grade have $M$ values (degrees of metapopulation feedback cohesion) falling within a range that is distinctly higher than $M$ values clustering in a different range. Because of this the conditions proposed here can also accommodate nesting relationships between evolving lineages of different grades.

${ }^{38} \mathrm{It}$ is possible to fail in both "more than whole" and "less than whole" ways simultaneously.
} 
climbing; the lesser feedback connections to that population were a drag on the overall magnitude or frequency of feedback relations in the metapopulation, so with that drag removed the magnitude or frequency of the feedback relations, and so the degree of metapopulation feedback cohesion, climbs markedly. To not fail in this way, a metapopulation would seemingly be satisfying an opposite condition: if any one population were subtracted from the metapopulation, the metapopulation's $M$ value would not significantly climb. If and only if a metapopulation satisfies this climbless subtraction condition, it averts "more than whole" failure and can be called a climbless subtraction metapopulation. 39 This is for relations between causal variables within it to be overall of much less magnitude or frequency than they would be in any more exclusive group that omits any of the constituent populations. Again this is a relative matter of degree.

\subsection{Third condition: non-zero $M$ value}

The third condition is a metapopulation's $M$ value being some distance from point zero. I leave "some" vague, intending only to capture the idea that some of the feedback relations discussed here are present in metapopulations made into evolving lineages by those relations.

\subsection{Fourth condition: descent condition}

This last condition is more tentative than the others but deserves consideration. It is being a numerically distinct ancestor or descendent of other metapopulations that satisfy the three preceding conditions. Including this condition along with the others should be attractive to those who conceive of lineages as essentially ancestor-descendant sequences in a sense that rules out processes akin to mere internal growth as sufficing for lineagehood. It will be less attractive to authors with more liberal views of lineagehood (e.g., Bouchard 2010).

Summing up, the feedback theory proposes that a metapopulation is an evolving lineage of at least one type if the frequency and magnitude of its feedback relations are such that it is both a tumble addition metapopulation (it averts "less than whole" failure) and a climbless subtraction metapopulation (it averts "more than whole" failure), and is some distance from point zero; we may wish to add: and it is an ancestor or descendant of other metapopulations that satisfy those preceding conditions. This is to suggest these three or four conditions are promising candidates for being among those constitutive of being an evolutionary lineage.

\section{Further Work}

Before summarizing the paper's argument, let me flag a few of the interesting ideas that could be developed and tested in light of the feedback theory of evolving lineages.

Expressing the theory with the help of variable spaces could clarify and help test the controversial idea that the species rank is especially distinct or objective in comparison to all more inclusive taxa ranks. 10 In the confines of the feedback theory, and as figure 3 was drawn to depict, that idea would predict that most metapopulations that clearly satisfy the conditions for being an evolving lineage would cluster within one reasonably distinct portion of $M$ space. The idea would allow that that portion extends with vague and irregular boundaries across a large portion of $M$ space, acknowledging various patterns in causal variables that suffice for being an evolving lineage of the species type. But the idea would suggest we could nonetheless draw some reasonably distinct (of course not sharp) threshold around this portion of $M$ space, with

\footnotetext{
${ }^{39}$ The previous sentence characterized this epistemically, the next does so ontologically.

${ }^{40}$ See Ereshefsky (1991) for a relatively old but still helpful review of this idea.
} 
this threshold being a significant distance from point zero, and those metapopulations outside of it and not very near point zero being relatively much more diffusely scattered between the species portion of $M$ space and point zero. Empirical testing could check if this is so. Claims about there being a reasonably distinct sub-species rank could be similarly tested.

Some version of species pluralism could be checked. Take groups that are already viewed as excellent candidates for being species. Plot their $M$ values in $M$ space. If they form more than one cluster, this fits with a kind of pluralism. And whether the pluralism threatens realism or unity about the species rank (Ereshefsky 1992b, 1998; Mishler 1999) could be assessed partly by the relative distance between species clusters. The greater the relative distances, the larger the threat; the smaller the relative distances, the weaker the threat.

The theory gives a framework in which to discuss disputes about particular metapopulations. Templeton (1989), for instance, implied that a metapopulation of poplars and one of cottonwoods were separate evolving species lineages, despite frequent gene flow between them. There is temptation for BSC advocates to disagree and see these as two parts of a larger species lineage. Templeton's case would seem supported to the extent that the poplars+cottonwoods metapopulation was significantly distant from point zero only along the $g$ axis; but with increased distance on other axes too, Templeton would lose support.

The relevance of candidate causal variables for $M$ values could be tested. Relevance would diminish for variables that tend across many cases to have high values mostly when other variables tend to low values; it would be supported for those variables whose higher values tend to coincide with higher values in others. And the legitimacy of that test-and assumptions of the feedback theory itself-could be tested in various ways. For instance, the more that independently judged "good species" display relatively high values on multiple variables, and supposedly "unlikely species" display quite mixed or low variable values, the more plausible the theory. When those predicted correspondences fail, the theory could offer checkable explanations. It could, for instance, explain lack of correspondence in a case of a "good species" judgment by suggesting that although only one or a few variable values were found to be high, they are probably very high; then we could check whether that is true. A converse type of explanation for failed "unlikely species" correspondence could be checked, and other explanations could be generated in either case. However, the more that various sorts of clumping in $M$ space are suggestive of evolving lineage patterns, the more reason we would have to discount disagreeable prior judgments about "good" and "unlikely" groups, and revise our underlying pre-theoretic assumptions to better accord with the feedback theory of evolving lineages.

\section{Summary}

The feedback theory of evolving lineages tries to shed light on what constitutes evolving lineages such as many species. This paper's conclusion is not, as noted in the introduction, that the feedback theory is true or probably true or now well enough supported that we should adopt it. Rather, it is that it would be worthwhile for some of the interdisciplinary community of researchers working on species and evolving lineages to collaboratively further develop and empirically test the feedback theory of evolving lineages elaborated here.

The main argument presented above for that conclusion can be summarized as taking modus ponens form. Premise 1, which was developed and defended mainly in Sections 2-5] of the paper, was that if the feedback theory of evolving lineages shows clear promise for meeting the exactness and comprehensiveness desiderata inferred from the strengths and weaknesses of existing work on evolving lineages (recall Table 1 and Table 2), then further development and 
testing of that theory would be worthwhile as concluded. Premise 2, elaborated and supported mainly in Sections 6-9, was that the theory indeed shows such promise.

\section{Acknowledgments}

For feedback on work leading to this paper the author thanks the editor and anonymous referees for this special issue, and James Luong, and audiences at the following conferences: Species in the Age of Discordance, Salt Lake City, UT, March 2017; Concordia Biology Department Retreat, Vendée, QC, September 2016; Inland Northwest Philosophy Conference (INPC), Pullman, WA, August 2014. Generous research funding was provided by the Fonds Québecois de la Recherche sur la Société et la Culture, grant \#2014-NP-176774.

\section{Literature cited}

Ausborn, Jessica, Harald Wolf, and Wolfgang Stein. 2009. "The Interaction of Positive and Negative Sensory Feedback Loops in Dynamic Regulation of a Motor Pattern.” Journal of Computational Neuroscience 27 (2): 245-57. doi:10.1007/s10827-009-0140-z.

Banerjee, Subhasis, and Indrani Bose. 2008. "Functional Characteristics of a Double Positive Feedback Loop Coupled with Autorepression.” Physical Biology 5 (4): 046008. doi:10.1088/14783975/5/4/046008.

Barbará, T., C. Lexer, G. Martinelli, S. Mayo, M. F. Fay, and M. Heuertz. 2008. "WithinPopulation Spatial Genetic Structure in Four Naturally Fragmented Species of a Neotropical Inselberg Radiation, Alcantarea imperialis, A. geniculata, A. glaziouana and A. regina (Bromeliaceae)." Heredity 101 (3): hdy200865. doi:10.1038/hdy.2008.65.

Barbará, T., G. Martinelli, M. F. Fay, S. J. Mayo, and C. Lexer. 2007. "Population Differentiation and Species Cohesion in Two Closely Related Plants Adapted to Neotropical High-Altitude 'Inselbergs', Alcantarea imperialis and Alcantarea geniculata (Bromeliaceae)." Molecular Ecology 16 (10): 1981-92. doi:10.1111/j.1365-294X.2007.03272.x.

Barker, Matthew J. 2010. “Specious Intrinsicalism.” Philosophy of Science 77 (1): 73-91.

Barker, Matthew J. 2017. "Eliminative Pluralism and Integrative Alternatives: The Case of species." The British Journal for the Philosophy of Science. doi:10.1093/bjps/axx057.

Barker, Matthew J., and Joel D. Velasco. 2013. “Deep Conventionalism about Evolutionary Groups.” Philosophy of Science 80 (5): 971-82. doi:10.1086/673923.

Barker, Matthew J., and Robert A. Wilson. 2010. "Cohesion, Gene Flow, and the Nature of Species." The Journal of Philosophy 107 (2): 59-77.

Baum, David A. 2009. “Species as Ranked Taxa.” Systematic Zoology 58 (1): 74-86. doi:10.1093/sysbio/syp011.

Baum, David A., Douglas J. Futuyma, Hopi E. Hoekstra, Richard E. Lenski, Allen J. Moore, Cahterine L. Peichel, Dolph Schluter, and Michael C. Whitlock. 2013. The Princeton Guide to Evolution. Princeton University Press.

Beatty, John. 1997. "Why Do Biologists Argue like They Do?” Philosophy of Science 64 (December): S432-43. doi:10.1086/392620.

Becks, Lutz, Stephen P. Ellner, Laura E. Jones, and Nelson G. Hairston. 2012. “The Functional Genomics of an Eco-evolutionary Feedback Loop: Linking Gene Expression, Trait Evolution, and Community Dynamics." Ecology Letters 15 (5): 492-501. doi:10.1111/j.1461-0248.2012.01763.x. 
Bensch, Staffan, Mats Grahn, Nils Müller, Laurene Gay, and Susanne Åkesson. 2009. “Genetic, Morphological, and Feather Isotope Variation of Migratory Willow Warblers Show Gradual Divergence in a Ring." Molecular Ecology 18 (14): 3087-96. doi:10.1111/j.1365-294X.2009.04210.x.

Bond, Jason E., and Amy K. Stockman. 2008. "An Integrative Method for Delimiting Cohesion Species: Finding the Population-Species Interface in a Group of Californian Trapdoor Spiders with Extreme Genetic Divergence and Geographic Structuring." Systematic Biology 57 (4): 62846. doi:10.1080/10635150802302443.

Bouchard, Frédéric. 2010. "Symbiosis, Lateral Function Transfer and the (Many) Saplings of Life." Biology \& Philosophy 25 (4): 623-41. doi:10.1007/s10539-010-9209-3.

Boyd, Richard. 1999. "Homeostasis, Species, and Higher Taxa." In Species: New Interdisciplinary Essays, edited by Robert A. Wilson, 141-85. Cambridge, MA: MIT Press.

Brooks, Daniel R., and Deborah A. McLennan. 2002. The Nature of Diversity: An Evolutionary Voyage of Discovery. University of Chicago Press.

Brooks, Daniel R., and E. O. Wiley. 1988. Evolution as Entropy: Towards a Unified Theory of Biology. 2nd edition. Chicago, IL: The University of Chicago Press.

Camargo, Arley, and Jack Sites Jr. 2013. “Species Delimitation: A. Decade After the Renaissance.” In The Species Problem: Ongoing Issues, edited by Igor Pavlinov. InTech. doi:10.5772/55046.

Caplan, Arthur L. 1980. "Have Species Become Déclassé?” PSA: Proceedings of the Biennial Meeting of the Philosophy of Science Association 1980: 71-82.

Caporale, Lynn Helena, and John Doyle. 2013. "In Darwinian Evolution, Feedback from Natural Selection Leads to Biased Mutations." Annals of the New York Academy of Sciences 1305 (1): 18-28. doi:10.1111/nyas.12235.

Carson, H. 1957. "The Species as a Field for Gene Recombination." In The Species Problem, edited by Ernst Mayr, 23-38. Washington: American Association for the Advancement of Science.

Cohan, Frederick M. 2011. "Are Species Cohesive?-A View from Bacteriology." In Population Genetics of Bacteria: A Tribute to Thomas $S$. Whittam, edited by S. T. Walk and P. C. H. Feng, 43-65. Washington, DC: ASM Press. http://www.asmscience.org/content/book/10.1128/ 9781555817114.ch05.

Coyne, Jerry A. 1992. "Much Ado about Species." Nature 357 (May): 289-90. doi:10.1038/357289a0.

Coyne, Jerry A., and H. A. Orr. 2004. Speciation. 1st ed. Sunderland, MA: Sinauer Associates, Inc.

Cracraft, Joel. 1989a. "Speciation and Its Ontology: The Empirical Consequences of Alternative Species Concepts for Understanding Patterns and Processes of Differentiation.” In Speciation and Its Consequences, edited by Daniel Otte and John A. Endler, 28-59. Sunderland, MA: Sinauer Associates Inc. http://ci.nii.ac.jp/naid/10014820123/.

- 1989b. "Species as Entities of Biological Theory." In What the Philosophy of Biology Is, 31-52. Nijhoff International Philosophy Series. Dordrecht: Springer. doi:10.1007/978-94-009-1169-7_ 3 .

Crane, J. 2004. "On the Metaphysics of Species." Philosophy of Science 71 (2): 156-73.

Darwin, Charles. 1859. On the Origin of Species by Means of Natural Selection: Or the Preservation of Favoured Races in the Struggle for Life. Reprint of 1st edition published by John Murray, London. Cambridge, MA: Harvard University Press, 1964.

Dayrat, Benoît. 2005. "Towards Integrative Taxonomy." Biological Journal of the Linnean Society 85 (3): 407-15. doi:10.1111/j.1095-8312.2005.00503.x. 
Devitt, M. 2008. “Resurrecting Biological Essentialism.” Philosophy of Science 75 (3): 344-82. doi:10.1086/593566.

Edwards, Scott V. 2009. "Is a New and General Theory of Molecular Systematics Emerging?" Evolution; International Journal of Organic Evolution 63 (1): 1-19. doi:10.1111/j.15585646.2008.00549.x.

Ehrlich, P. R., and P. H. Raven. 1969. “Differentiation of Populations.” Science 165 (899): 1228-32.

Eldredge, Niles, and Joel Cracraft. 1980. Phylogenetic Patterns and the Evolutionary Process: Method and Theory in Comparative Biology. New York: Columbia University Press.

Ellstrand, Norman C. 2014. "Is Gene Flow the Most Important Evolutionary Force in Plants?" American Journal of Botany 101 (5): 737-53. doi:10.3732/ajb.1400024.

Ereshefsky, Marc. 1991. "Species, Higher Taxa, and the Units of Evolution." Philosophy of Science 58 (1): 84-101.

—. , ed. 1992a. The Units of Evolution: Essays on the Nature of Species. The MIT Press.

—. 1992b. "Eliminative Pluralism." Philosophy of Science 59 (4): 671-90.

—. 1998. "Species Pluralism and Anti-Realism.” Philosophy of Science 65 (1): 103-20.

- 2001. The Poverty of the Linnaean Hierarchy: A Philosophical Study of Biological Taxonomy. 1st ed. Cambridge, MA: Cambridge University Press.

Fisher, Ronald A. 1930. The Genetical Theory of Natural Selection. 1st edition. London: Clarendon Press.

Ghiselin, Michael T. 1974. “A Radical Solution to the Species Problem.” Systematic Zoology 23 (4): 536-44.

—. 1987. "Species Concepts, Individuality, and Objectivity." Biology and Philosophy 2 (2): 127-43. doi:10.1007/BF00057958.

Godfrey-Smith, Peter. 2009. Darwinian Populations and Natural Selection. Oxford: Oxford University Press.

Grant, Vern. 1980. "Gene Flow and the Homogeneity of Species Populations.” Biologisches Zentralblatt 99: 157-69.

Grigg, E. R. N. 1965. The Trail of the Invisible Light, from X-Strablen to Radiobiology. Springfield, Ill.: Charles C. Thomas Publishers, Ltd.

Haber, Matthew H. 2012. "Multilevel Lineages and Multidimensional Trees: The Levels of Lineage and Phylogeny Reconstruction.” Philosophy of Science 79 (5): 609-623.

-. 2013. "Species Problems." Metascience 22: 333-42.

Hellberg, Michael E., Ronald S. Burton, Joseph E. Neigel, and Stephen R. Palumbi. 2002. "Genetic Assessment of Connectivity Among Marine Populations.” Bulletin of Marine Science 70 (Supplement): 273-90.

Hennig, Willi. 1966. Phylogenetic Systematics. Urbana, IL: University of Illinois Press.

Hull, David L. 1976. “Are Species Really Individuals?” Systematic Biology 25 (2): 174-91. doi:10.2307/2412744.

—. 1981. "Kitts and Kitts and Caplan on Species." Philosophy of Science 48: 141-52.

Irwin, Darren E. 2009. “Incipient Ring Speciation Revealed by a Migratory Divide.” Molecular Ecology 18 (14): 2923-2925.

Kimbel, William H., and Yoel Rak. 1993. "The Importance of Species Taxa in Paleoanthropology and an Argument for the Phylogenetic Concept of the Species Category." In Species, Species Concepts

๑ OPEN ACCESS - PTPBIO.ORG 
and Primate Evolution, edited by William H. Kimbel and Lawrence B. Martin, 461-84. New York: Springer.

Kitcher, Philip. 1984. “Species.” Philosophy of Science 51 (2): 308-33.

Kitts, David B., and David J. Kitts. 1979. "Biological Species as Natural Kinds.” Philosophy of Science 46 (4): 613-22.

Lande, Russell. 1980. "Genetic Variation and Phenotypic Evolution During Allopatric Speciation.” The American Naturalist 116 (4): 463-79.

Lehtonen, Jussi, and Hanna Kokko. 2012. "Positive Feedback and Alternative Stable States in Inbreeding, Cooperation, Sex Roles and Other Evolutionary Processes." Philosophical Transactions of the Royal Society B: Biological Sciences 367 (1586): 211-21. doi:10.1098/rstb.2011.0177.

Mallet, James. 1995. "A Species Definition for the Modern Synthesis." Trends in Ecology and Evolution 10 (July): 294-99. doi:10.1016/S0169-5347(00)89105-3.

Mallet, James, Nora Besansky, and Matthew W. Hahn. 2016. "How Reticulated Are Species?” BioEssays 38 (2): 140-49. doi:10.1002/bies.201500149.

Mayden, R. L. 1997. "A Hierarchy of Species Concepts: The Denouement in the Saga of the Species Problem." In Species: The Units of Biodiversity, edited by Michael F. Claridge, H. A. Dawah, and M. R. Wilson, 54:381-424. Boca Raton, FA: Chapman \& Hall.

- 2013. "Species, Trees, Characters, and Concepts: Ongoing Issues, Diverse Ideologies, and a Time for Reflection and Change." In The Species Problem: Ongoing Issues, edited by Igor Pavlinov. InTech. doi:10.5772/55046.

Mayr, Ernst. 1963. Animal Species and Evolution. 1st ed. Belknap Press.

. 1970. Populations, Species, and Evolution. Abridged. Belknap Press of Harvard University Press.

- 2000a. "A Defense of the Biological Species Concept." In Species Concepts and Phylogenetic Theory: A Debate, edited by Quentin Wheeler and Rudolf Meier, 161-66. New York, NY: Columbia University Press.

- 2000b. "The Biological Species Concept." In Species Concepts and Phylogenetic Theory: A Debate, edited by Quentin Wheeler and Rudolf Meier, 17-29. New York, NY: Columbia University Press.

Miao, Zhanshuai, Fengde Chen, Jiamin Liu, and Liqiong Pu. 2017. "Dynamic Behaviors of a Discrete Lotka-Volterra Competitive System with the Effect of Toxic Substances and Feedback Controls." Advances in Difference Equations 2017 (1): 112. doi:10.1186/s13662-017-1130-5.

Millstein, Roberta L. 2010. "The Concepts of Population and Metapopulation in Evolutionary Biology and Ecology." In Evolution Since Darwin: The First 150 Years, edited by M. A. Bell, D. J. Futuyma, W. F. Eanes, and J. S. Levinton. Sinauer.

Mishler, B. D. 1999. “Getting Rid of Species?” In Species: Nerw Interdisciplinary Essays, edited by Robert A. Wilson, 307-315. MIT Press.

Mishler, B. D., and R. N. Brandon. 1987. "Individuality, Pluralism, and the Phylogenetic Species Concept." Biology \& Philosophy 2 (4): 397-414. doi:10.1007/BF00127698.

Mishler, B. D., and M. J. Donoghue. 1982. “Species Concepts: A Case for Pluralism.” Systematic Zoology 31: 491-503.

Morjan, Carrie L., and Loren H. Rieseberg. 2004. "How Species Evolve Collectively: Implications of Gene Flow and Selection for the Spread of Advantageous Alleles.” Molecular Ecology 13 (6): 1341-56. doi:10.1111/j.1365-294X.2004.02164.x. 
Naomi, Shun-Ichiro. 2011. "On the Integrated Frameworks of Species Concepts: Mayden's Hierarchy of Species Concepts and de Queiroz's Unified Concept of Species.” Journal of Zoological Systematics and Evolutionary Research 49 (3): 177-84. doi:10.1111/j.1439-0469.2011.00618.x.

Neto, Celso. 2016. "Rethinking Cohesion and Species Individuality." Biological Theory 11 (3): 138-49. doi:10.1007/s13752-016-0243-5.

Padial, José M., Aurélien Miralles, Ignacio De la Riva, and Miguel Vences. 2010. "Review: The Integrative Future of Taxonomy." Frontiers in Zoology 7: 1-14.

Pfeuty, Benjamin, and Kunihiko Kaneko. 2009. "The Combination of Positive and Negative Feedback Loops Confers Exquisite Flexibility to Biochemical Switches.” Physical Biology 6 (4): 046013. doi:10.1088/1478-3975/6/4/046013.

Pigliucci, Massimo. 2003. "Species as Family Resemblance Concepts: The (Dis-)Solution of the Species Problem?” BioEssays 25 (6): 596-602. doi:10.1002/bies.10284.

Pulido, Francisco. 2007. “The Genetics and Evolution of Avian Migration.” BioScience 57 (2): 165-74. doi:10.1641/B570211.

Queiroz, Kevin de. 1998. "The General Lineage Concept of Species, Species Criteria, and the Process of Speciation: A Conceptual Unification and Terminological Recommendations." In Endless Forms: Species and Speciation, edited by D. J. Howard and S. H. Berlocher, 57-75. New York, NY: Oxford University Press.

- 2005a. "A Unified Concept of Species and Its Consequences for the Future of Taxonomy." Proceedings of the California Academy of Sciences 56: 196-215.

_. 2005b. "Ernst Mayr and the Modern Concept of Species." Proceedings of the National Academy of Sciences 102 (suppl_1): 6600-6607. doi:10.1073/pnas.0502030102.

—. 2007. "Species Concepts and Species Delimitation.” Systematic Biology 56 (6): 879-86. doi:10.1080/10635150701701083.

Queller, David C., and Joan E. Strassmann. 2009. "Beyond Society: The Evolution of Organismality.” Philosophical Transactions of the Royal Society of London B: Biological Sciences 364 (1533): 3143-55. doi:10.1098/rstb.2009.0095.

Richards, Richard A. 2010. The Species Problem: A Philosophical Analysis. 1st ed. Cambridge University Press.

Robertson, Douglas S., and M. C. Grant. 1996a. "Feedback and Chaos in Darwinian Evolution: I. Theoretical Considerations." Complexity 2 (1): 10-14.

- 1996b. "Feedback and Chaos in Darwinian Evolution: II. Numerical Modelling." Complexity 2 (2): $18-30$.

Sazima, Ivan, Stefan Vogel, and Marlies Sazima. 1989. "Bat Pollination of Encholirium glaziovii, a Terrestrial Bromeliad.” Plant Systematics and Evolution 168 (3-4):167-79. doi:10.1007/BF00936097.

Sazima, Marlies, Silvana Buzato, and Ivan Sazima. 1999. "Bat-Pollinated Flower Assemblages and Bat Visitors at Two Atlantic Forest Sites in Brazil." Annals of Botany 83 (6): 705-12. doi:10.1006/anbo.1999.0876.

Schaffer, Jonathan. 2016. “The Metaphysics of Causation." In The Stanford Encyclopedia of Philosophy, edited by Edward N. Zalta, Fall 2016. Metaphysics Research Lab, Stanford University. https: //plato.stanford.edu/archives/fall2016/entries/causation-metaphysics/.

Schlick-Steiner, Birgit C., Florian M. Steiner, Bernhard Seifert, Christian Stauffer, Erhard Christian, and Ross H. Crozier. 2010. "Integrative Taxonomy: A Multisource Approach to Exploring Biodiversity." Annual Review of Entomology 55: 421-38. doi:10.1146/annurev-ento-112408-085432.

๑ OPEN ACCESS - PTPBIO.ORG 
Schmid-Egger, Christian, Kees van Achterberg, Rainer Neumeyer, Jérôme Morinière, and Stefan Schmidt. 2017. "Revision of the West Palaearctic Polistes Latreille, with the Descriptions of Two Species - an Integrative Approach Using Morphology and DNA Barcodes (Hymenoptera, Vespidae)." ZooKeys 713 (February): 53-112. doi:10.3897/zookeys.713.11335.

Simpson, George Gaylord. 1961. Principles of Animal Taxonomy. 1ST ed. Columbia University Press.

Sober, Elliott. 1980. "Evolution, Population Thinking, and Essentialism.” Philosophy of Science 47 (3): 350-83.

—. 1999. "The Multiple Realizability Argument against Reductionism.” Philosophy of Science 66 (4): 542-64.

Stanford, P. Kyle. 2010. Exceeding Our Grasp: Science, History, and the Problem of Unconceived Alternatives. New York; Oxford: Oxford University Press.

Stegenga, Jacob. 2014. "Population Pluralism and Natural Selection." The British Journal for the Philosophy of Science, September, axu003. doi:10.1093/bjps/axu003.

Sterelny, Kim. 2011. "Darwinian Spaces: Peter Godfrey-Smith on Selection and Evolution." Biology E Philosophy 26 (4): 489-500. doi:10.1007/s10539-010-9244-0.

Templeton, Alan. 1989. "The Meaning of Species and Speciation: A Genetic Perspective." In The Units of Evolution: Essays on the Nature of Species, edited by Marc Ereshefsky, 159-83, 1992. Cambridge, MA: MIT Press.

Turner, Scott. 2008. "Homeostasis, Complexity, and the Problem of Biological Design." Emergence: Complexity and Organization 10 (2): 76-89.

Van Valen, Leigh. 1976. “Ecological Species, Multispecies, and Oaks.” Taxon 25 (2/3): 233-39.

Wadhams, George H., and Judith P. Armitage. 2004. "Making Sense of It All: Bacterial Chemotaxis.” Nature Reviews Molecular Cell Biology 5 (12): 1024-37. doi:10.1038/nrm1524.

Wiley, E. O. 1981. Phylogenetics: The Theory and Practice of Phylogenetic Systematics. 1st ed. Wiley-Liss.

Wiley, E. O., and Richard Mayden. 2000. “The Evolutionary Species Concept.” In Species Concepts and Phylogenetic Theory: A Debate, edited by Quentin Wheeler and Rudolf Meier, 70-89. New York, NY: Columbia University Press.

Wilkins, John. 2018. Species: A History of the Idea. 2nd Edition. Berkeley, CA: University of California Press.

Will, Kipling W., Brent D. Mishler, Quentin D. Wheeler, and Vincent Savolainen. 2005. "The Perils of DNA Barcoding and the Need for Integrative Taxonomy." Systematic Biology 54 (5): 844-51. doi:10.1080/10635150500354878.

Wilson, Jack. 1999. Biological Individuality: The Identity and Persistence of Living Entities. Cambridge University Press.

Wilson, Robert A. 2005. Genes and the Agents of Life: The Individual in the Fragile Sciences Biology. Cambridge University Press.

Wilson, Robert A., Matthew J. Barker, and Ingo Brigandt. 2007. "When Traditional Essentialism Fails: Biological Natural Kinds.” Pbilosophical Topics 35 (1-2): 189-215.

Zachos, Frank E. 2016. Species Concepts in Biology: Historical Development, Theoretical Foundations and Practical Relevance. Switzerland: Springer.

(C) 2019 Author(s) This is an open-access article distributed under the terms of the Creative Commons Attribution 4.0 International license, which permits anyone to download, copy, distribute, display, or adapt the text without asking for permission, provided that the creator(s) are given full credit.

ISSN 2475-3025

๑ OPEN ACCESS - PTPBIO.ORG 